\title{
Uncertainties in Grout Penetrability Measurements; Evaluation and Comparison of Filter pump, Penetrability Meter and Short Slot
}

\author{
A. Nejad Ghafar $\cdot$ S. Ali Akbar $\cdot$ M. Al-Naddaf $\cdot$ A. Draganovic $\cdot$ \\ S. Larsson
}

Received: 21 January 2016/Accepted: 20 August 2017/Published online: 30 August 2017

(C) The Author(s) 2017. This article is an open access publication

\begin{abstract}
To measure grout penetrability in fractured hard rock, various measuring instruments have been developed over the years. Penetrability meter and Filter pump have been designed to use in both the lab and the field. Short slot has been applicable mainly in the lab due to its complexity. The fact, that these instruments have been built based on different assumptions, limitations, and test conditions, makes their results occasionally in contradict. Deficiency in design of the instruments as well as the methods of evaluating grout penetrability is additionally a basis for uncertainty in results. This study is an experimental effort to determine and thoroughly perceive the nature of the most governing uncertainties in grout penetrability measurements. The test apparatus, procedure, and method used to evaluate the grout penetrability in both Penetrability meter and Filter pump were thus modified. The aim was to control the corresponding uncertainties and make their limitations and test conditions as similar as possible with the ones in Short slot. The results suggested that to obtain a more realistic evaluation of the grout penetrability, measurement should be accomplished at both the high and the low pressures with sufficient grout volume
\end{abstract}

A. Nejad Ghafar $(\bowtie) \cdot$ S. Ali Akbar .

M. Al-Naddaf · A. Draganovic · S. Larsson

Division of Soil and Rock Mechanics, Department of

Civil and Architectural Engineering, KTH Royal Institute of Technology, 10044 Stockholm, Sweden

e-mail: ali.nejad.ghafar@byv.kth.se using Short slot. Moreover, application of both Filter pump and Penetrability meter is no longer recommended due to the revealed uncertainties.

Keywords Penetrability · Filtration · Filter pump · Penetrability meter $\cdot$ Short slot $\cdot$ Cement-based grout

\section{Introduction}

Cement-grouting is a common solution for rock sealing, whereas a key factor to success is to achieve sufficient penetration length in fractures (Houlsby 1990; Lombardi 2003; Warner 2004; Gustafson and Stille 2005; Fransson 2008; Gustafson et al. 2013; Stille 2015). Filtration, generally defined as separation of the suspended solid and the liquid phases of a fluid, limits the grout spread in rock, due to arching/bridging of the cement particles before a constriction through the fractures (Rushton et al. 2000; Eriksson et al. 2004; Hernqvist et al. 2009; Rafi and Stille 2015). Several instruments have been developed over the years to measure the filtration and the penetrability of the cement-based grout, with a summary of the test conditions and the evaluation methods presented in Table 1. The filter-pump and the penetrability-meter, developed by Hansson (1995) and Eriksson and Stille (2003) respectively, are two of the most commonly used instruments in Scandinavia applicable in both the lab and the field due to the simplicity of their 
Table 1 A summary of the grout penetrability measuring instruments

\begin{tabular}{|c|c|c|c|c|c|c|c|}
\hline & \multirow[t]{2}{*}{ Instrument } & \multirow{2}{*}{$\begin{array}{l}\text { Evaluation } \\
\text { method }\end{array}$} & \multicolumn{4}{|l|}{ Test conditions } & \multirow[t]{2}{*}{ Developed/investigated } \\
\hline & & & Filtration media & $\begin{array}{l}\text { Stop } \\
\text { mechanism }\end{array}$ & $\begin{array}{l}\text { Pressure } \\
\text { (bars) }\end{array}$ & $\begin{array}{l}\text { Grout volume } \\
\text { (L) }\end{array}$ & \\
\hline 1 & Sand column & $\mathrm{Ra}-\mathrm{T}-\mathrm{V}$ & Sand & $\mathrm{C}-\mathrm{F} 3-\mathrm{Re}$ & 2.6 & 10 & Axelsson et al. (2009) \\
\hline 2 & $\begin{array}{l}\text { Pressure } \\
\text { chamber }\end{array}$ & $\mathrm{Ra}$ & $\begin{array}{l}\text { Fleece fine sand soft } \\
\text { rock }\end{array}$ & $\mathrm{F} 4$ & 1.6 & N.A. & $\begin{array}{l}\text { Gandais and Delmas } \\
\text { (1987) }\end{array}$ \\
\hline 3 & Filter pump & $\mathrm{T}$ & Wire mesh & $\mathrm{F} 2$ & 0.5 & 0.3 & Hansson (1995) \\
\hline 4 & $\begin{array}{l}\text { Penetrability } \\
\text { meter }\end{array}$ & $\mathrm{T}$ & Wire mesh & $\mathrm{F} 2$ & $1.0 / 2.0$ & 1.0 & $\begin{array}{l}\text { Eriksson and Stille } \\
\text { (2003) }\end{array}$ \\
\hline 5 & NES method & W & Slot & $\mathrm{F} 1$ & $0-20$ & N.A. & Sandberg (1997) \\
\hline 6 & $\begin{array}{l}\text { Nobuto } \\
\text { method }\end{array}$ & W & Slot & $\mathrm{F} 1$ & $10-50$ & Unlimited & Nobuto et al. (2008) \\
\hline 7 & PenetraCone & $\mathrm{Vt}$ & Slot & $\mathrm{F} 2$ & $1.5 / 3.0 / 5.0$ & Unlimited & $\begin{array}{l}\text { Axelsson and Gustafson } \\
\text { (2010) }\end{array}$ \\
\hline 8 & Short slot & $\mathrm{W}$ & Slot & $\mathrm{F} 2$ & $0-15$ & 1.7 & $\begin{array}{l}\text { Draganovic and Stille } \\
\text { (2011) }\end{array}$ \\
\hline 9 & Long Slot & $\mathrm{W}-\mathrm{P}$ & Slot & F2-Re & $0-15$ & 1.7 & $\begin{array}{l}\text { Draganovic and Stille } \\
\text { (2014) }\end{array}$ \\
\hline
\end{tabular}

$F 1$ filtration at connection between a borehole and a fracture, $F 2$ filtration at constriction through a fracture, $F 3$ filtration, where the grains enter the aperture but gradually separate from the flow and plug the pores, $F 4$ filtration through the walls of the fracture due to the porosity of the rock matrix and existing micro-cracks, $C$ clogging, where the grains are stuck before entering the aperture, $R e$ resistance, where the grouting pressure reaches the frictional resistance, $R a$ raise of the water column, $T$ total volume of passed grout, $V$ visual inspection of the sand column, $V t$ visual inspection of the flow transition from undisturbed flow to dripping and from dripping to the flow stop, $P$ pressure-time measurement, $W$ weight-time measurement, N.A. not available

performances. Short slot has been designed based on geometry and pressure conditions much closer to the rock grouting conditions in field; however, it is a bit more complicated in performance and rather applicable in the lab (Draganovic and Stille 2011).

Comparison of the results obtained from different test apparatus has been previously done by several researchers with various objectives. There were, however, many disagreements between the outcomes of those studies. This was principally due to the fact that the instruments have been designed based on different assumptions, limitations, and test conditions. For instance, the results obtained from Penetrability meter and Filter pump were mostly in contradiction with the ones obtained from Short slot (Draganovic and Stille 2014). Hjertström (2001) using the NES method, a smooth slot approximately similar to Short slot, and Eriksson and Stille (2003) using Penetrability meter illustrated that the penetrability is independent of water to cement $(w / c)$ ratio. However, Hansson (1995) by comparing the results of Filter pump with the ones on the sand column and the smooth slot, Eklund and Stille (2008) using Penetrability meter, Axelsson et al. (2009) using the sand column, and Draganovic and Stille (2011) using Short slot disclosed that increasing the $(w / c)$ ratio improves the penetrability. According to Hansson (1995), adding super plasticizer improves the grout penetrability using the smooth slot and Filter pump. However, Eriksson and Stille (2003) showed that use of super plasticizer has no significant influence on penetrability using Penetrability meter. A deep survey in all those studies revealed that the corresponding uncertainties and contradictions are mainly originated in association with:

(a) The applied pressures

(b) The designated grout volumes

(c) The type and the geometry of the filtration areas, e.g., the geometry of the constrictions

(d) The methods used to evaluate the grout penetrability in terms of $b_{\text {min }}$ and $b_{\text {crit }}$

(a) The Applied Pressure

One of the weak points of Filter pump is primarily the operator-dependency of the applied pressure, which is definitely not identical in experiments performed neither by different operators nor by an exhausted operator after 
plenty of performances. According to Hansson (1995), the ordinary applied pressure in Filter pump is tolerably around 0.5 bar. In Penetrability meter, the grout tank pressure is regularly set to 1 bar during the experiments (Eriksson and Stille 2003). The ordinary applied pressure of 15 bar in Short slot, however, is considerably higher than the other two instruments (Draganovic and Stille 2011). It is well known that the grout penetrability is improved by increasing the pressure (Eriksson et al. 1999; Hjertström 2001; Nobuto et al. 2008; Draganovic and Stille 2011; Stille et al. 2012). Therefore, the penetrability measurement is undeniably dependent on the grouting pressure and the experiments on identical grout samples under different pressures should definitely reveal diverse or even contradictory results.

Furthermore, in grouting operations in the field, the grout pressure at the beginning of a fracture is equal to the pressure applied at the grouting borehole (relatively high). This pressure gets close to zero or the ground water pressure at the grout front depending on the saturation condition. The grout pressure along the fracture is, however, somewhat in between and also varies at each point during the grout spread. It should be highlighted that we are mainly concerned on the grout pressure at the constrictions within a fracture, where the filtration of the cement particles mostly occurs (Draganovic and Stille 2011, 2014). This suggests the significance of the magnitude of the applied pressure in order to measure the grout penetrability more realistic.

\section{(b) The Designated Grout Volume}

According to Eriksson and Stille (2003, 2008), grout filtration tendency will reasonably be increased by increasing the volume of the grout passed through the mesh filter. The more the grout volume, the greater is the probability of accumulation and clogging of the cement particles and clusters before the constrictions. It should be noticed that the capacity of Filter pump is about $0.3 \mathrm{~L}$ compared with the designated grout volume of $1 \mathrm{~L}$ in Penetrability meter and $2.6 \mathrm{~L}$ capacity of the grout container in Short slot. This difference in the grout volume will possibly generate different results in examining identical grout samples, disregarding the influences of uneven pressures and geometries.

\section{(c) The Constriction Geometry}

Even though, the key question and consequently the geometry in design of different instrument have been different, they have been all designed to evaluate grout penetrability. For instance, the mesh geometry used in Filter pump and Penetrability meter has been mainly designed to replicate a fracture opening, whereas the slot geometry used in Short slot is to study the grout penetrability at the constrictions within a fracture. Filter pump, due to the simplicity of its performance, is currently used for assessment and quality control of cement and mixing process in field. However, as illustrated by Hansson (1995), Eriksson and Stille (2003), and Eklund and Stille (2008), they have been all used to study the influence of varying parameters on grout penetrability.

The corresponding diversity in the type and the geometry of the filtration areas, e.g., the geometry of the constrictions in different instruments is also an origin of dissimilar results. In Penetrability meter and Filter pump, the thickness of the woven metal mesh filter is somewhat less than $100 \mu \mathrm{m}$, depending on the size of the employed steel wires. In Short slot, the length of the constriction, however, is about 100 times longer equal to $10 \mathrm{~mm}$ (Draganovic and Stille 2011). Consequently, the resisting friction against the grout flow along the thickness of the mesh filters/constrictions in both Penetrability meter and Filter pump will reasonably be negligible, compared with that in Short slot. Furthermore, the effective area in the instruments is different, which leads to different results in examining identical grout samples.

\section{(d) The Evaluation Method}

The quantities of $b_{\min }$ and $b_{\text {crit }}$, developed by Eriksson and Stille (2003), have been the most common used criteria representing the filtration tendency and the penetrability of the grout (Draganovic and Stille 2014). By definition, the $b_{\min }$ is the minimum fracture aperture a grout 


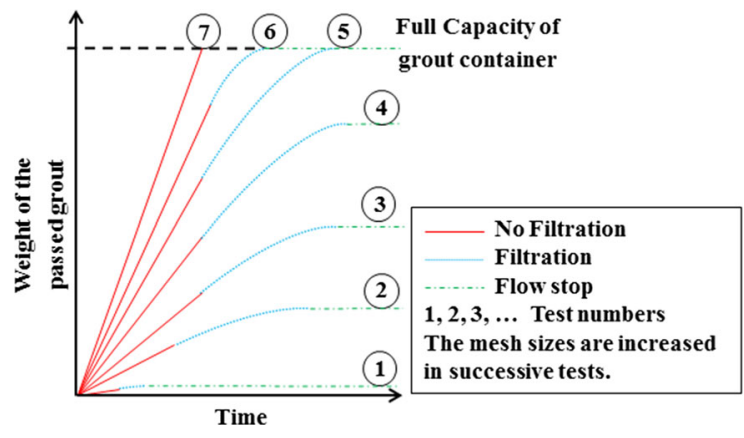

Fig. 1 Application of weight-time measurement to visualize the uncertainty in evaluation of $b_{\text {crit }}$ using the total weight of passed grout

can penetrate at all, whereas the $b_{\text {crit }}$ represents the minimum fracture aperture a grout can penetrate without filtration. In Penetrability meter and Filter pump, the total volume of grout passed through each filter is regularly used as the method to estimate the values of $b_{\min }$ and $b_{\text {crit }}$. Each experiment is started using the minimum mesh size, enlarged stepwise in successive tests. The narrowest mesh filter, through which the total designated grout volume can entirely pass, represents the value of $b_{\text {crit }}$. The uncertainty of this evaluation method becomes discernible at the mesh sizes sufficiently close to the $b_{\text {crit }}$, using a stepwise bottom-up approach towards the $b_{\text {crit }}$. To visualize this, the measure of weight in time as depicted in Fig. 1 is employed. In this evaluation, a linear relation between the weight and time is an indication of no-filtration versus a non-linear relation which indicates the filtration (Draganovic and Stille 2011). As seen in the figure, in the vicinity of the $b_{\text {crit }}$, i.e., in the tests 5 and 6 , despite of slight filtration at the mesh surface, the remained opening is still adequate to let the entire designated grout capacity pass through. Using the total volume of passed grout as the evaluation method, the value of the $b_{\text {crit }}$ is therefore estimated smaller, i.e., equal to the mesh size in test 5 , while the weight-time measurement reveals a greater value equal to the mesh size in test 7 with no filtration at all. In this study, the uncertainties (a)-(d) above are addressed by a series of experiments. Various aspects are examined and discussed that influence the penetrability and evaluation of the parameters $b_{\text {min }}$ and $b_{\text {crit }}$. We aim to perform the tests using different instruments at conditions as similar as possible, in order to have a fair comparison between the results. Our intention is to study the reasons that cause the corresponding differences between the results. Since Short slot is considered to best replicate the filtration process at a constriction in a rock fracture, the test apparatus and procedure in both Penetrability meter and Filter pump were modified to approach the similar test conditions as in Short slot. Comparison of the results in such conditions provided the opportunity to better evaluate the reliability and functionality of the instruments. Furthermore, the weighttime and the pressure-time evaluation methods are proposed as more accurate alternatives for evaluating the grout penetrability with Filter pump and Penetrability meter. The work presented here intends to support the development of instruments to measure the filtration and the penetrability of the cement-based grout.

\section{Materials and Methods}

\subsection{Adjustment of Filter Pump}

Adjustment of Filter pump was to increase the applied pressure from 0.5 to 1 bar as in Penetrability meter, to exclude its operator-dependency and to improve repeatability. It was also to employ the weight-time measurement in order to observe the filtration evolution during the experiments. A $20 \mathrm{~kg}$ mass was therefore suspended from the handle of Filter pump using a steel cable passed through two designated rollers (Fig. 2). A grout pot was then suspended from the lab ceiling through an S-shaped load cell, RSCC $C 3 / 50 \mathrm{~kg}$ from $H B M$. Each experiment was regularly started using the minimum mesh size of $26 \mu \mathrm{m}$ attached to the instrument inlet. To run the test, the operator had to release the mass, whereas the instrument inlet was submerged in the grout pot. The grout is consequently sucked inside the instrument, whereas the cement particles build an arch/bridge at the openings in mesh surface (Fig. 2). After the full stroke, the handle had to be kept in maximum position, 
Fig. 2 Schematic depiction of modified filter pump and details of arching/bridging at mesh filter, (1) DAQ-data acquisition system, (2) filter pump, (3) load cell

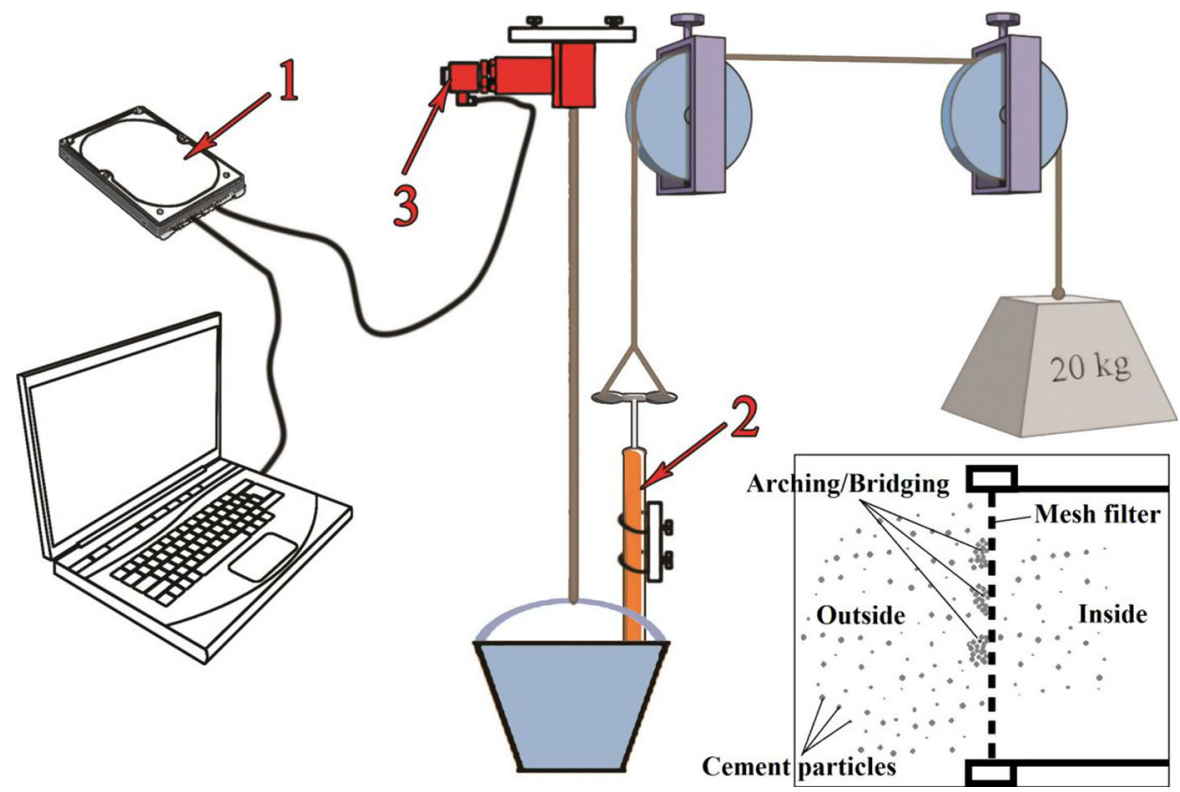

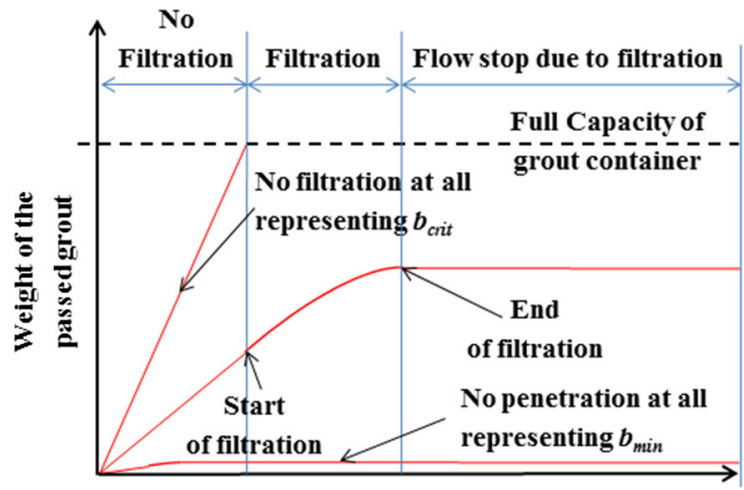

Time

Fig. 3 Evaluation of $b_{\min }$ and $b_{\text {crit }}$ using the weight-time measurement

while the weight record continued until the flow stop. The process had to be successively repeated by enlarging the mesh sizes as far as no filtration observed during the experiment. The weight-time measurement, as explained earlier, was the method used to distinguish the filtration. The maximum mesh size with negligible passed grout was therefore a representation of the $b_{\text {min }}$, while the minimum mesh size with no filtration at all was an indication of the $b_{\text {crit }}$ (Fig. 3).

\subsection{Adjustment of Penetrability Meter}

Adjustment of Penetrability meter was primarily to follow the filtration evolution in time using the two evaluation methods; the measures of weight and pressure in time and compare it with the filtration process in Short slot. In this way, the similarity of the filtration process in the filter mesh and the slot's constriction or a real fracture could be better studied. It was also to increase the designated grout volume from 1 to $2.6 \mathrm{~L}$ to make it similar to Short slot. The constriction geometry, i.e. the mesh and the pressure condition were approximately similar to those in modified Filter pump. To register the grout weight in time, the grout tank was therefore suspended from the lab ceiling through an S-shaped load cell, RSCC C3/ $50 \mathrm{~kg}$ from $H B M$ (Fig. 4). To provide a constant pressure of 1 bar, a high-pressure gas tank was then connected to the grout tank via a regulator. To register the pressure variation in time, a pressure transmitter, P15RVA1/20BAR from $H B M$, was appended to the tank. Finally, to replicate a fracture constriction, a cap holder, keeping the mesh filter in position, was attached to the system.

Each experiment was started using the minimum mesh size of $26 \mu \mathrm{m}$. The grout in grout tank was first pressurized up to the designated 1 bar pressure. By opening the outlet valve and start of the grout flow, the cement particles began to build an arch/bridge at the openings in mesh surface, similar to what occurs in filter pump (Fig. 4), whereas the weight and pressure were recorded in time. The process was then successively repeated by enlarging the mesh sizes as far as no 
Fig. 4 Schematic depiction of modified penetrability meter and details of arching/ bridging at mesh filter, (1) gas tank, (2) pressure regulator, (3) pressure sensor, (4) grout tank, (5) load cell, (6) DAQ-data acquisition system, (7) outlet valve, (8) filter holder and mesh filter

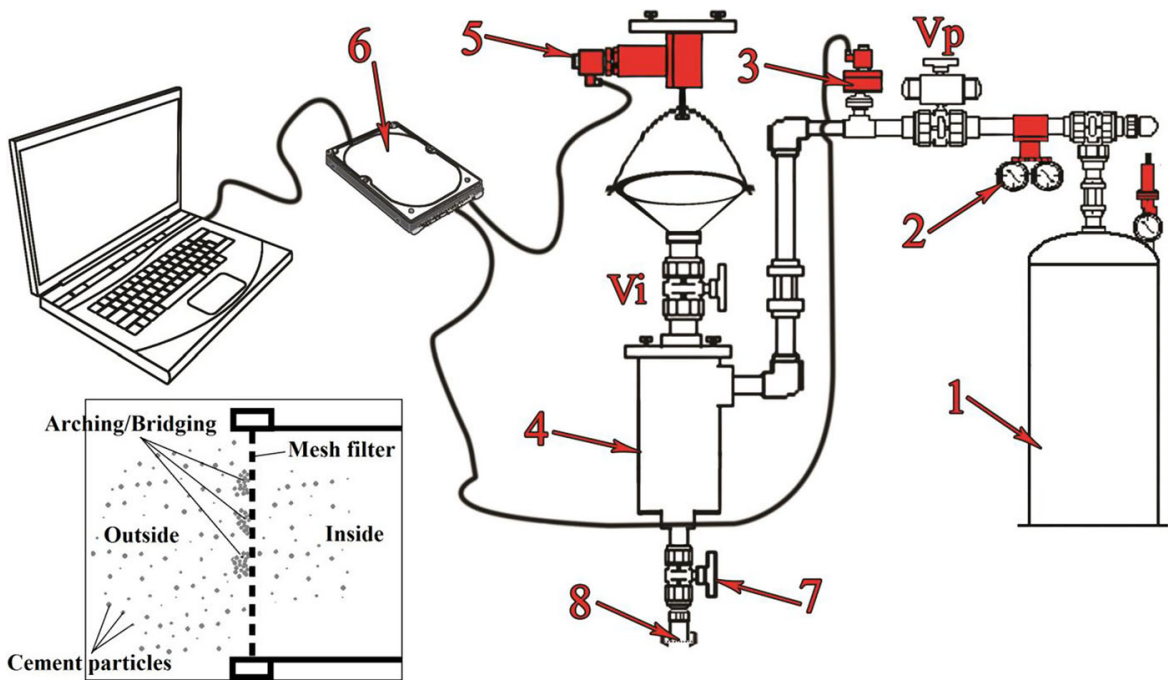

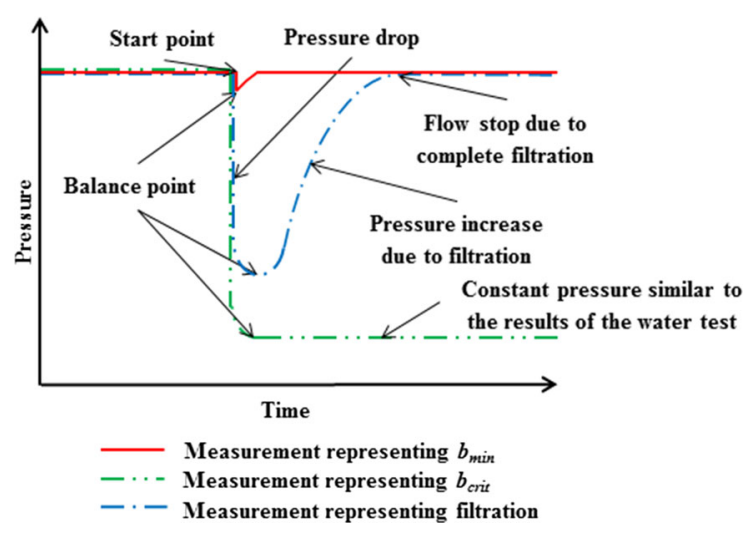

Fig. 5 Monitoring filtration and evaluating the $b_{\min }$ and $b_{\text {crit }}$ using the pressure-time measurement

filtration was observed. To identify the filtration and to evaluate the values of $b_{\min }$ and $b_{\text {crit }}$, weight and pressure in time were alternately measured. The weight-time measurement was similar to that in modified Filter pump but the designated grout volume was $2.6 \mathrm{~L}$ in modified Penetrability meter versus $0.3 \mathrm{~L}$ in modified Filter pump. Therefore, the evaluated value of $b_{\text {crit }}$ using modified Penetrability meter was expected to be greater than the values obtained from modified Filter pump, due to the higher probability of filtration associated with the higher volume of passed grout.

In the pressure-time measurement, when the flow began, a sharp drop in pressure regularly occurred until the balance point, in which the outflow of grout was compensated by the inflow of gas (Fig. 5). Subsequently, the pressure was maintained constant

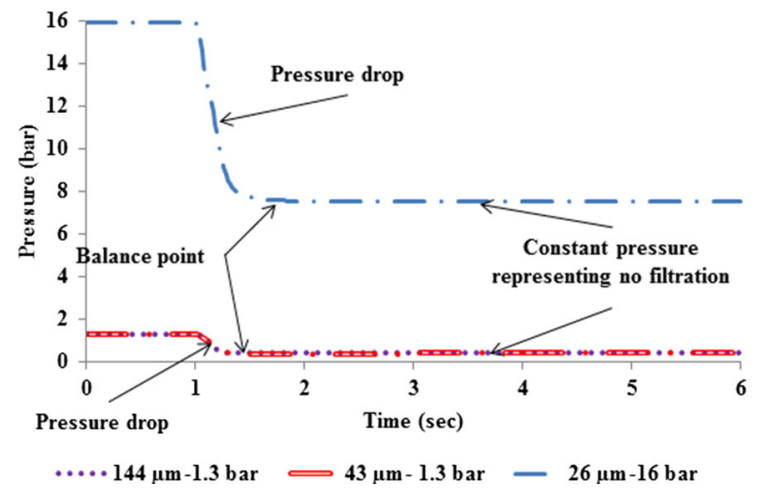

Fig. 6 Results of the experiments conducted with water, evaluated by the pressure-time method, using modified penetrability meter with 26,43 and $144 \mu \mathrm{m}$ mesh filters under 1.3 and 16 bar pressures

provided that the grout was stable without filtration tendency. Such behavior is ideally observed in water. To validate this, the pressure state after the balance point was examined in a couple of water tests under the applied pressures of 1.3 and 16 bar, using the mesh sizes of 26, 43, and $144 \mu \mathrm{m}$ (Fig. 6). There was no sign of pressure increase subsequent to the balance point in any of the test results, indicating no filtration. On the contrary, in examining a grout with filtration tendency, the pressure state after the balance point showed a continuous increase. The mesh opening and consequently the grout flow progressively decreased due to the filtration of the cement particles. In this approach, a mesh filter maintaining the pressure constant after the balance point is considered to be representative as the $b_{\text {crit }}$, while a mesh filter resulting in a negligible 


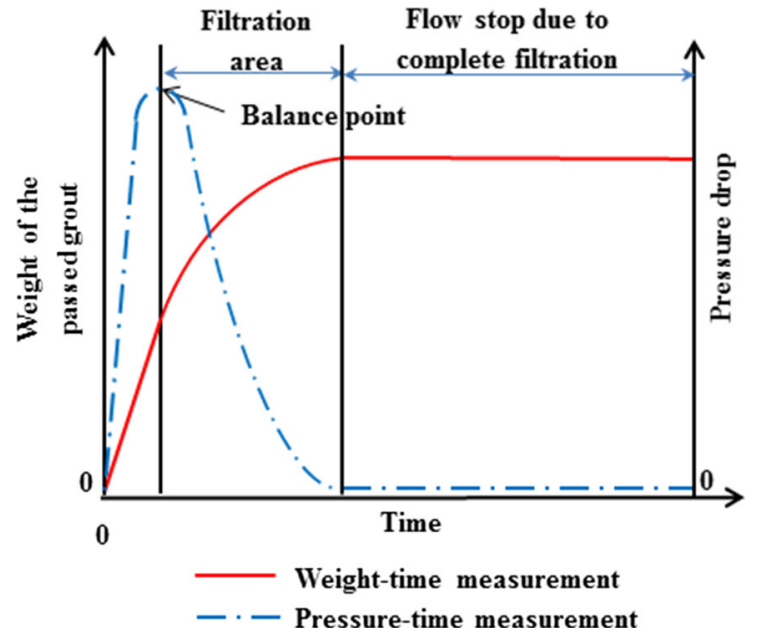

Fig. 7 Theoretical depictions of the weight-time and the pressure drop-time methods

pressure drop, followed by an immediate flow stop represents the $b_{\text {min }}$ (Fig. 5). Note that in this study, variation of pressure in time is presented in the form of pressure drop versus time, to display the results, all starting from the zero level. The results of both the weight-time and the pressure drop-time measurements should reveal the same values of $b_{\min }$ and $b_{\text {crit }}$ as shown in Fig. 7.

\subsection{Short Slot}

The test apparatus in the experiments with Short slot was similar to that in modified Penetrability meter except for the cap holder which was replaced by a disk-shaped slot with different constrictions appended to the grout tank (Fig. 8). In this method, the cement particles build an arch/bridge at the constriction. The method used to evaluate the grout penetrability was the weight-time measurement similar to those in modified Filter pump and penetrability meter. More details of the test setup and procedure can be found in Draganovic and Stille (2011).

\subsection{Material Selection and Mixing}

The grout comprised of Sika ${ }^{\circledR}$ Injektering 30 from Sika Sverige $A B$, a low-alkali injection cement based on Portland cement with $d_{95}$ of $30 \mu \mathrm{m}$ (95\% of the cement particles pass through a $30 \mu \mathrm{m}$ sieve), using a water to cement ratio $(w / c)$ of 0.8 as a common used grout recipe in Sweden. A dispersing agent, Sika ${ }^{\circledR}$ iFlow-1, was also employed with $0.5 \%$ of concentration of the cement weight to improve the grout penetrability by generating electrostatic and/or steric repulsion between the cement particles. A rotor-stator lab mixer from VMA was employed to mix the grout with $10,000 \mathrm{rpm}$. The mixing period was $4 \mathrm{~min}$. After 1 min of mixing, the superplasticizer was added to the mixture. The prepared grout (approximately $2.8 \mathrm{~L}$ in each batch) was subsequently used to fill the grout tank and run the test immediately.

\subsection{Test Plan}

The experiments were conducted based on the test plan presented in Table 2. Due to the limited pressure

Fig. 8 Schematic depiction of short slot and details of arching/bridging at the constriction, (1) gas tank, (2) pressure regulator, (3) pressure sensor, (4) grout tank, (5) load cell, (6) DAQdata acquisition system, (7) short slot

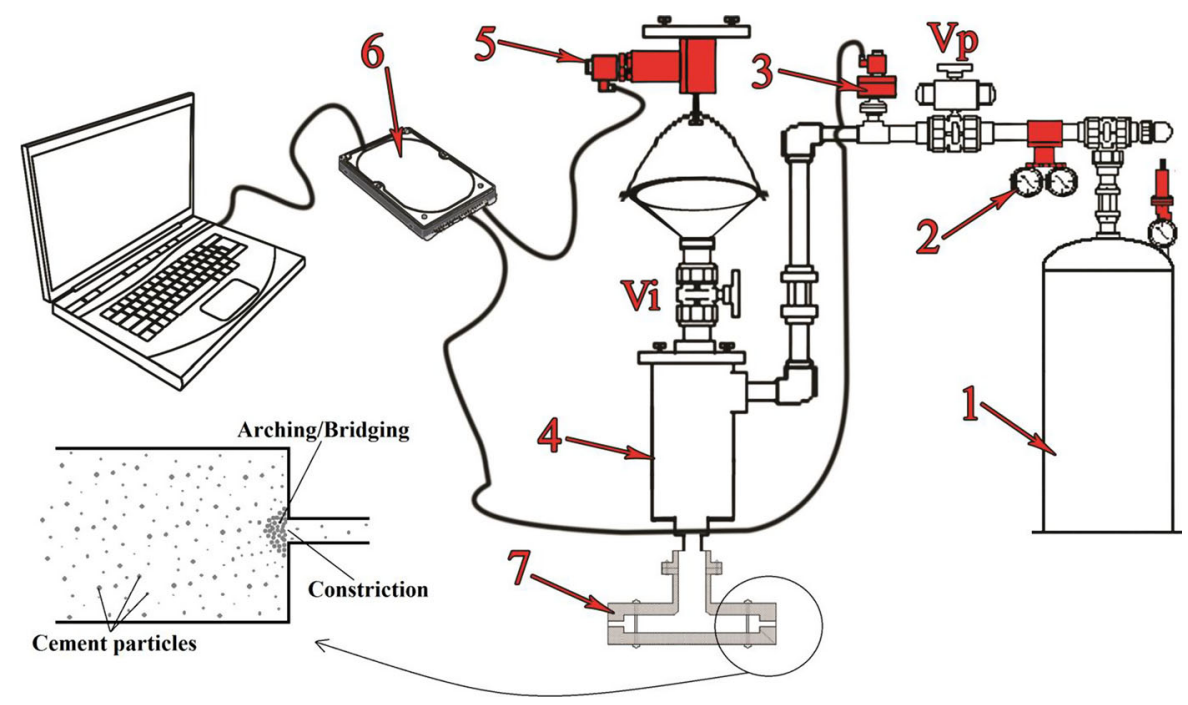


capacity of both Filter pump and Penetrability meter, the applied pressure of 1 bar was determined for all experiments except for the test group 6, conducted with 15 bar pressure using Short slot. Test groups 1 and 2, using ordinary and modified Filter pump, were designed to visualize the uncertainties and examine the effectiveness of the modifications. Test groups 3 and 4 were thereafter performed using modified Penetrability meter to compare the efficiency of the weight-time and the pressure-time evaluation methods and the evaluated $b_{\text {min }}$ and $b_{\text {crit }}$ with these methods. To investigate the influence of the applied pressure, as a governing origin of the contradiction, test groups 5 and 6 were thus organized under application of 1 and 15 bar pressure using Short slot. The tests were continuously re-performed to check the repeatability of the adjusted instruments and methods.

\section{Results}

A summary of the values of $b_{\text {min }}$ and $b_{c r i t}$ evaluated for the same materials and recipe using the aforementioned instruments with different pressure conditions, designated grout volume, geometries, and evaluation methods are presented in Table 3.

\subsection{Penetrability Measurement Using Filter Pump}

The results of the experiments examined by ordinary Filter pump using the weight-time measurement evaluation are presented in Fig. 9. The experiments with 26 and $35 \mu \mathrm{m}$ mesh filters illustrated negligible passed grouts and immediate flow stop due to the instant filtration, while the efforts with $43 \mu \mathrm{m}$ mesh filter disclosed some minor grout flows. The value of $b_{\text {min }}$ was therefore evaluated as $35 \mu \mathrm{m}$. The measurements with 54-90 $\mu \mathrm{m}$ mesh filters resulted noisy graphs with varied mass flow rates, showing a very poor repeatability. Considering the total volume of passed grout to evaluate the values of $b_{\text {crit }}$, the result would be $77 \mu \mathrm{m}$, since the grout tank was completely filled in all three repetitions. However, using the weight-time measurement evaluation, a fair estimation of the $b_{\text {crit }}$ will approximately be $90 \mu \mathrm{m}$, since some filtration is detectable in the results of the $77 \mu \mathrm{m}$ mesh filter.

The results of the experiments examined by modified Filter pump using the weight-time 
Table 3 Summary of the results

OFP ordinary filter pump, $M F P$ modified filter pump, $M P M$ modified penetrability meter, $S S$ short slot, $T$ total volume of passed grout, $W$ weight-time,

$P$ pressure-time

Fig. 9 Penetrability evaluated by ordinary filter pump with 26-90 $\mu \mathrm{m}$ mesh filters using the weight-time measurement

\begin{tabular}{llccc}
\hline Test device & Evaluation method & Pressure $(\mathrm{bar})$ & $\mathrm{b}_{\min }(\mu \mathrm{m})$ & $\mathrm{b}_{\text {crit }}(\mu \mathrm{m})$ \\
\hline OFP & $\mathrm{T}$ & 1 & 35 & 77 \\
OFP & $\mathrm{W}$ & 1 & 35 & 90 \\
MFP & $\mathrm{T}$ & 1 & 43 & 61 \\
MFP & $\mathrm{W}$ & 1 & 43 & 77 \\
MPM & $\mathrm{W}$ & 1 & 43 & 200 \\
MPM & $\mathrm{P}$ & 1 & 35 & 200 \\
SS & $\mathrm{W}$ & 1 & 70 & 200 \\
SS & $\mathrm{W}$ & 15 & 26 & 50 \\
\hline
\end{tabular}
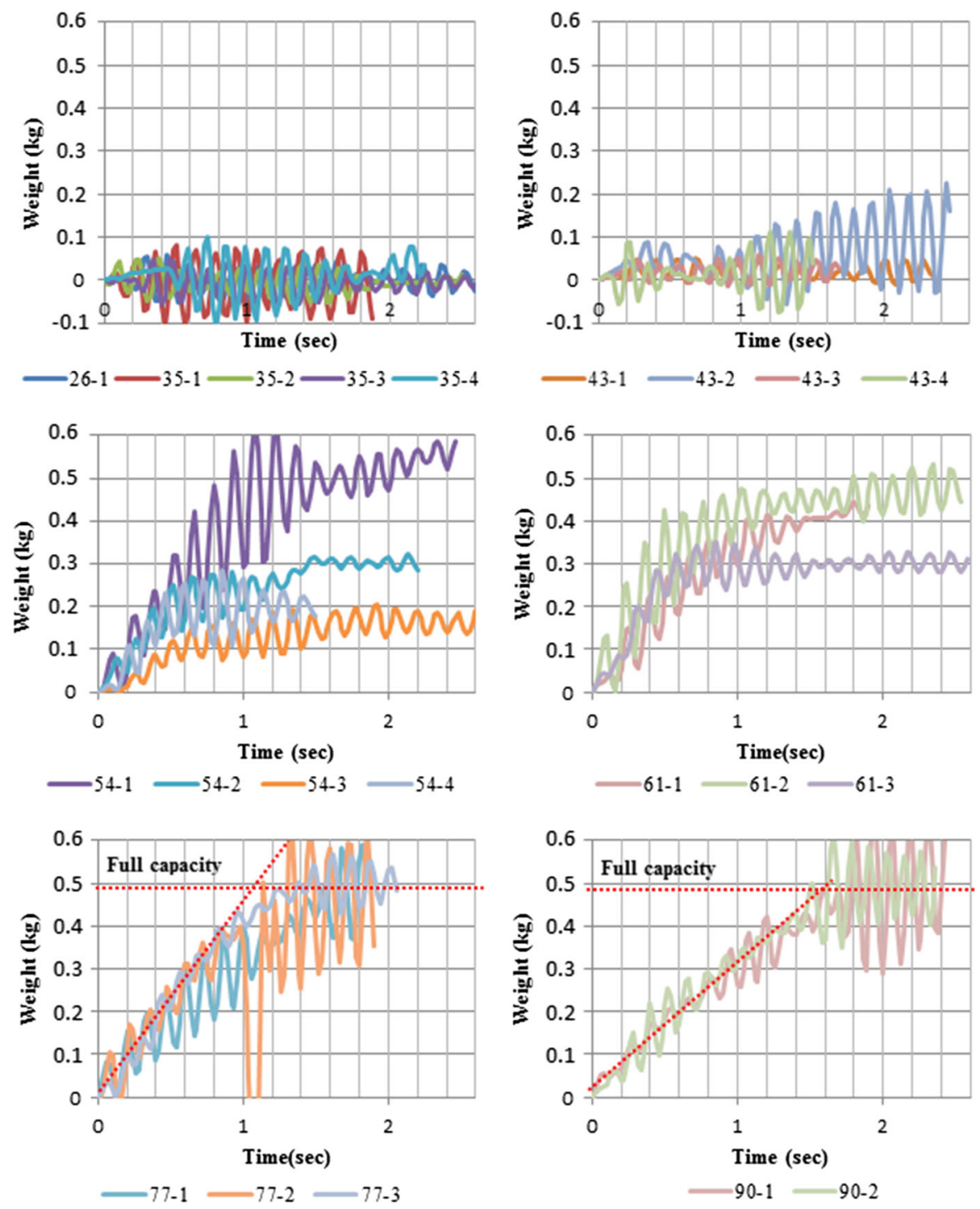

measurement evaluation are presented in Figs. 10 and 11 . The experiments with 35 and $43 \mu \mathrm{m}$ mesh filters illustrated negligible passed grouts and immediate flow stop due to the instant filtration (Fig. 10). The value of $b_{\min }$ was therefore evaluated as $43 \mu \mathrm{m}$. However, the measurements with $54 \mu \mathrm{m}$ 
Fig. 10 Penetrability evaluated by modified filter pump with 35-104 $\mu \mathrm{m}$ mesh filters using the weight-time measurement

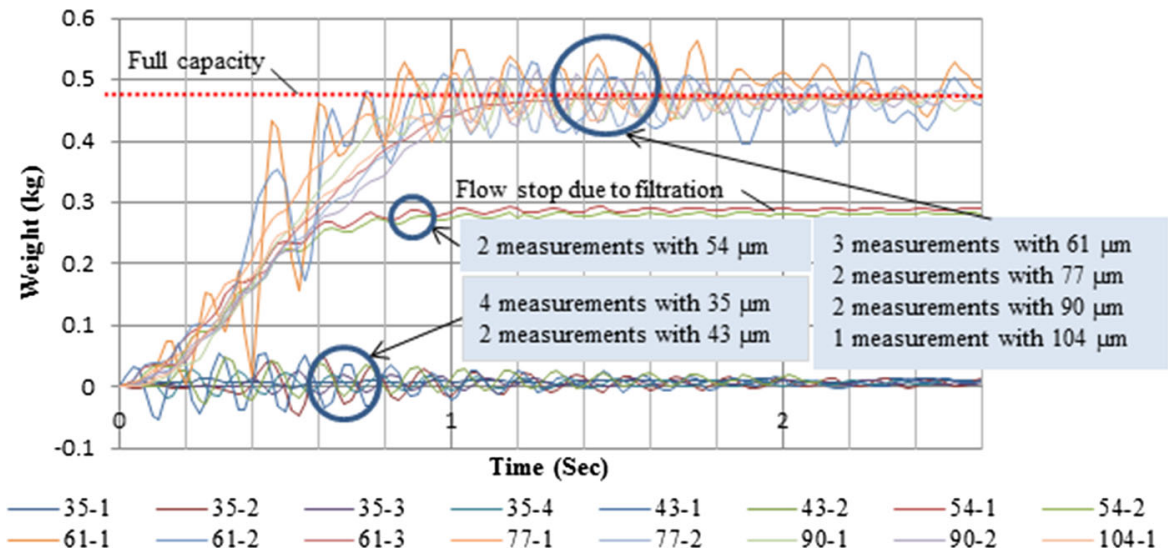

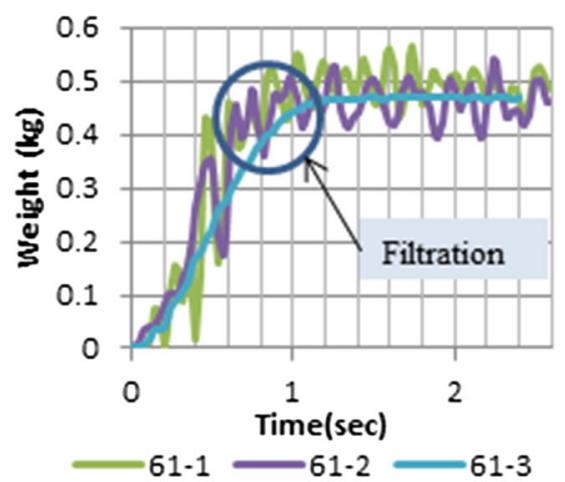

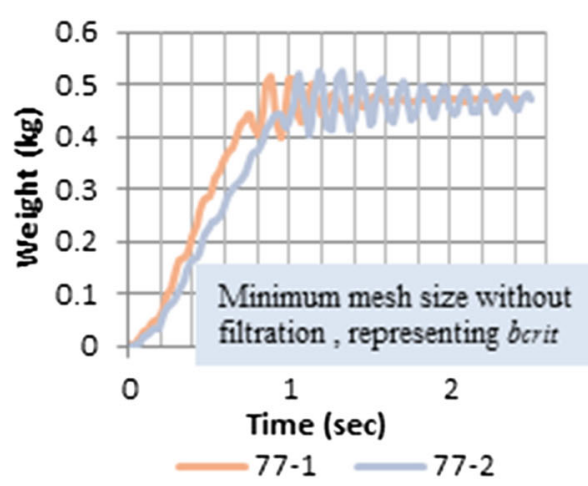

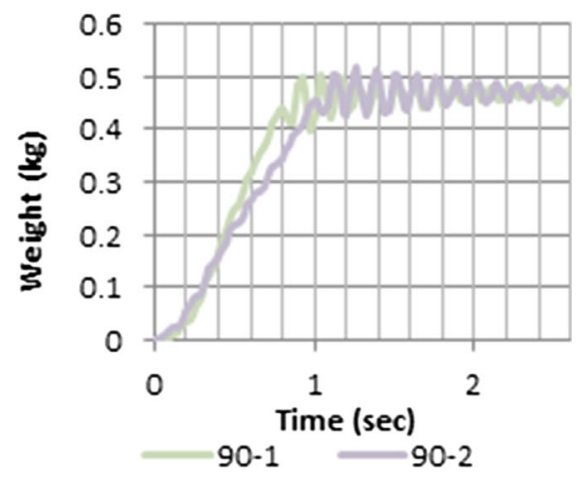

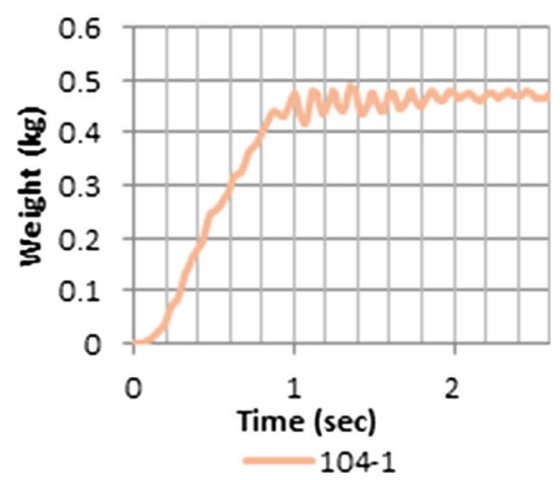

Fig. 11 Penetrability of samples (based on recipe 1) evaluated by modified filter pump with $61-104 \mu \mathrm{m}$ mesh filters using the weighttime measurement

mesh filter showed limited grout flow and partial filling of the instrument capacity followed by flow stop due to filtration. The measurements with 61-104 $\mu \mathrm{m}$ mesh filters revealed approximately similar mass flow rates, showing a better repeatability compared with ordinary Filter pump. Considering the total volume of passed grout to evaluate the values of $b_{\text {crit }}$, the result would be $61 \mu \mathrm{m}$, since the whole instrument capacity was completely filled in all experiments with the 61-104 $\mu \mathrm{m}$ mesh filters. However, a fair estimation of the $b_{\text {crit }}$ will possibly be greater than $61 \mu \mathrm{m}$, i.e. $77 \mu \mathrm{m}$, using the weighttime evaluation method, due to the visualized filtration in the results of $61 \mu \mathrm{m}$ mesh filter (Fig. 11). 
Fig. 12 Penetrability evaluated by modified penetrability meter with 35-144 $\mu \mathrm{m}$ mesh filters using the weight-time measurement
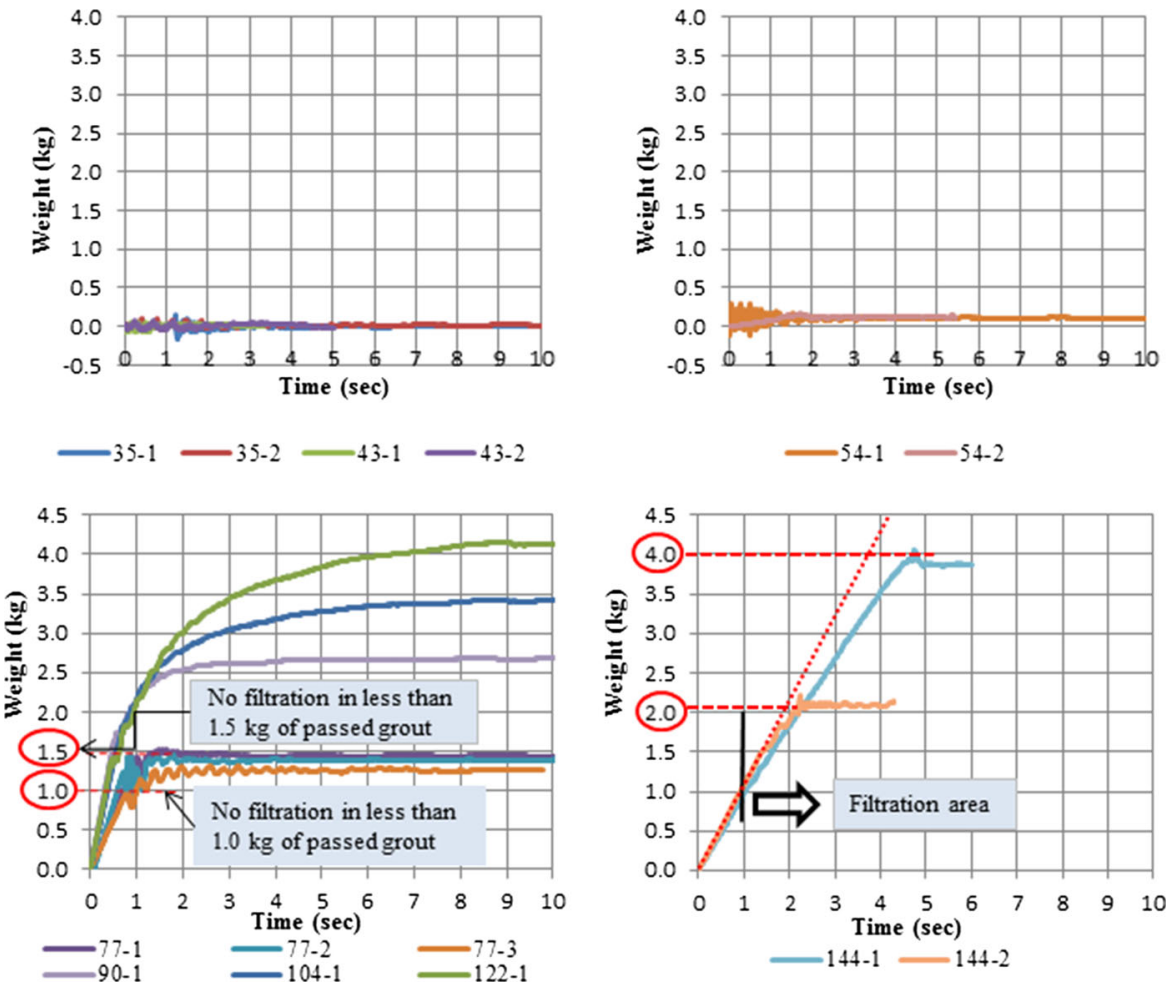

3.2 Penetrability Measurement Using Penetrability Meter

The results of the experiments examined by modified Penetrability meter using the weight-time measurement are presented in Fig. 12. The experiments with 35 and $43 \mu \mathrm{m}$ mesh filters showed negligible passed grouts and immediate flow stop due to the instant filtration, while the efforts with $54 \mu \mathrm{m}$ mesh filter disclosed some minor grout flows. The value of $b_{\text {min }}$ was therefore evaluated as $43 \mu \mathrm{m}$. Subsequently, the experiments with $77 \mu \mathrm{m}$ mesh filter presented no sign of filtration in less than $1.0 \mathrm{~kg}$ of the passed grout with a satisfactory repeatability. The experiments with 90-122 $\mu \mathrm{m}$ mesh filters further displayed no sign of filtration in less than $1.5 \mathrm{~kg}$ of the passed grout, whereas after this limit the nonlinear graphs represent the filtration. The measures with $144 \mu \mathrm{m}$ mesh filter examined with 2.0 and $4.0 \mathrm{~kg}$ of the passed grout, however, illustrated a minor non-linearity in the graphs, representing a slight filtration. This implies that the value of $b_{\text {crit }}$ is greater than $144 \mu \mathrm{m}$, approximately $200 \mu \mathrm{m}$, provided that the amount of passed grout is between 2.0 and $4.0 \mathrm{~kg}$.
The results of the experiments examined by modified Penetrability meter using the pressure-time measurement evaluation are depicted in Fig. 13. The attempts with $35 \mu \mathrm{m}$ mesh filter, presenting a negligible pressure drop of less than 0.1 bar with no grout flow, were representative for the value of $b_{\text {min }}$. However, in the experiments with wider openings/ mesh sizes where accompanied by considerable grout flows, the pressure drops were no longer negligible and rose progressively in successive tests. Subsequent to the balance point, the pressure drop returned back to its initial zero value in the attempts with $35-104 \mu \mathrm{m}$ mesh filters, representing the filtration. The time period to obtain the pressure drop back to zero from the balance point was also increased by enlarging the mesh filter (Fig. 13). The minor reductions in pressure drop after the balance point, depicted in the results of the experiments with $144 \mu \mathrm{m}$ mesh filter, were an indication of filtration, which were all interrupted by reaching the driving gas to the outlet. However, in the experiment with $200 \mu \mathrm{m}$ mesh filter the interruption occurred at the balance point before appearance of any filtration. The value of $b_{c r i t}$ was therefore evaluated as $200 \mu \mathrm{m}$. 
Fig. 13 Penetrability evaluated by modified penetrability meter with 35-200 $\mu \mathrm{m}$ mesh filters using the pressure-time measurement
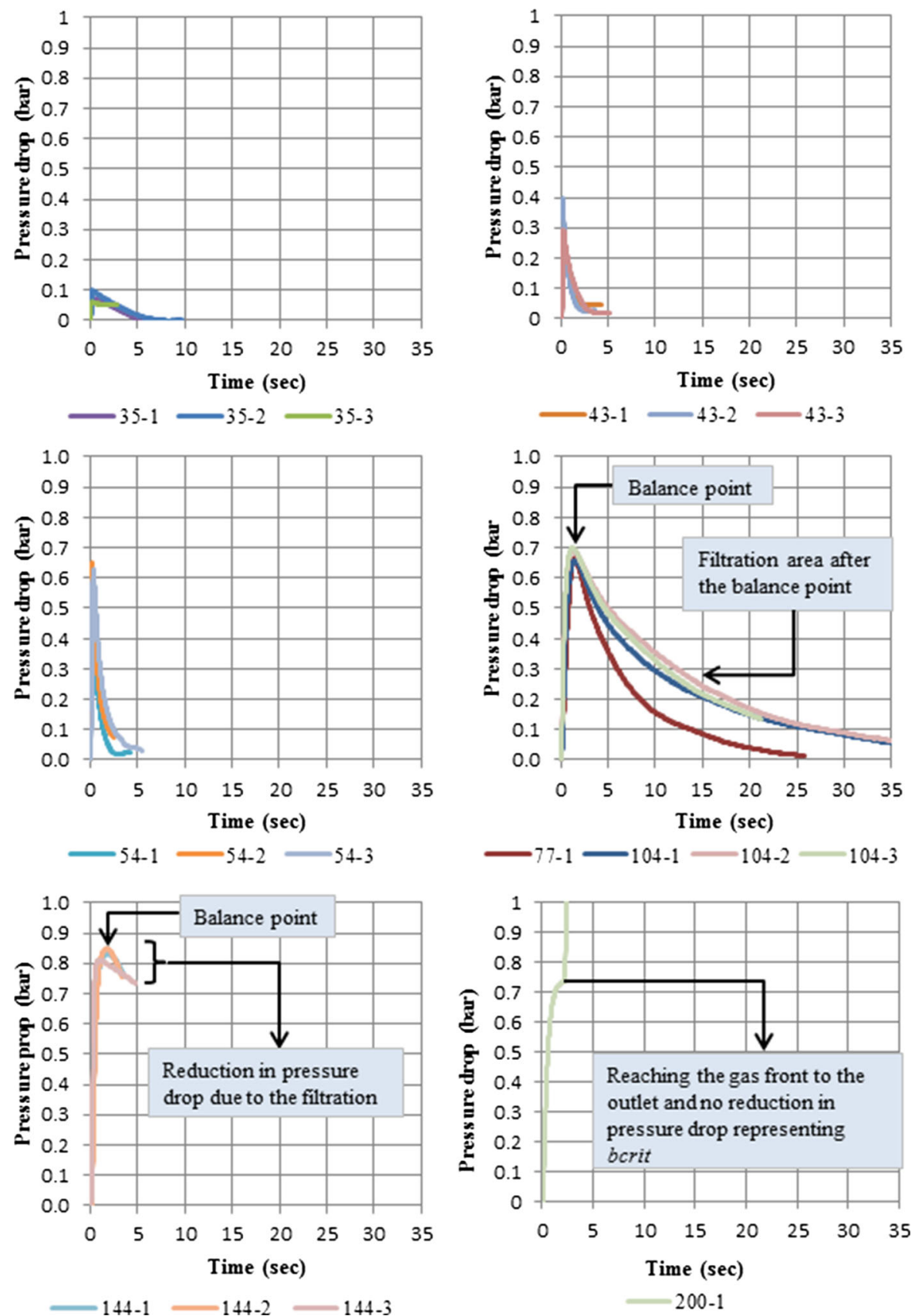

\subsection{Penetrability Measurement Using Short Slot}

The results of the experiments performed with Short slot with 1 bar grout pressure using the weight-time evaluation are shown in the left diagram in Fig. 14. The experiments with $70 \mu \mathrm{m}$ aperture size showed a negligible passed grout and immediate flow stop due to the instant filtration. The value of $b_{\min }$ was therefore evaluated as $70 \mu \mathrm{m}$. The experiments with 169 and $177 \mu \mathrm{m}$ aperture sizes, however, illustrated non-linear relations, representing considerable filtration. This implies that the value of $b_{\text {crit }}$ is evaluated greater than $177 \mu \mathrm{m}$, e.g., approximately $200 \mu \mathrm{m}$.

The results of the experiments performed with Short slot with 15 bar grout pressure using the weight-time evaluation are presented in the right diagram in Fig. 14. 
Fig. 14 Penetrability evaluated by short slot under 1 bar (left) and 15 bar (right) pressures, using the weight-time measurement
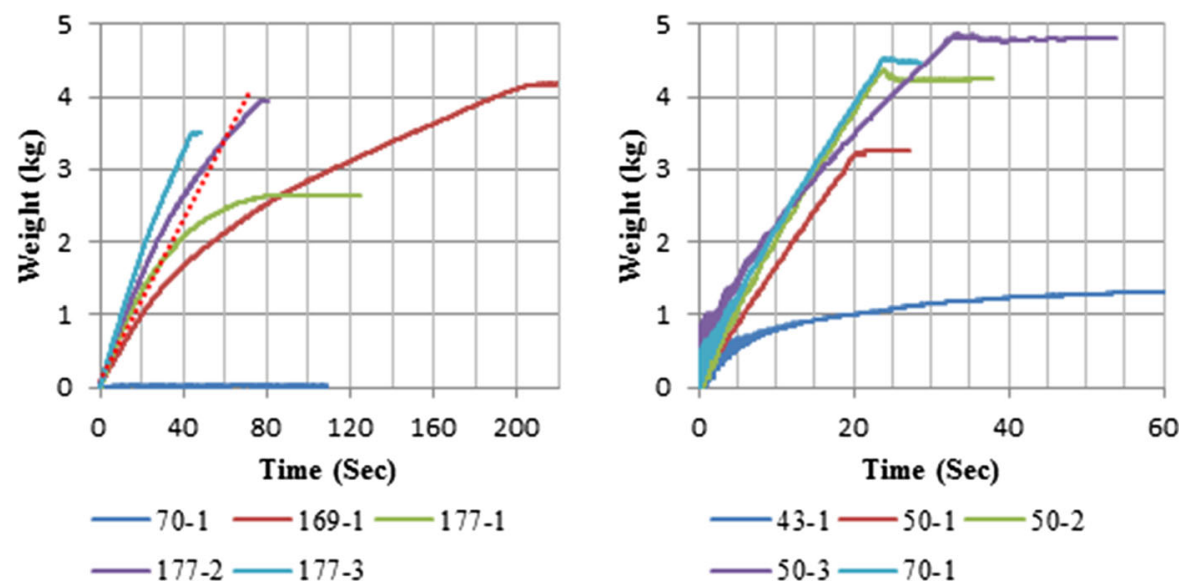

The experiments with $43 \mu \mathrm{m}$ aperture size showed a nonlinear relation with considerably quick filtration followed by the flow stop after $1.3 \mathrm{~kg}$ of the passed grout. Therefore, a fair estimation for the value of $b_{\text {min }}$ will definitely be lower than $43 \mu \mathrm{m}$. The attempts with 50 and $70 \mu \mathrm{m}$ aperture sizes, however, illustrated linear relations with similar trends, representing no filtration at all. The value of $b_{\text {crit }}$ is therefore evaluated as $50 \mu \mathrm{m}$.

According to Eklund (2005), a rule of thumb in hard rock grouting developed by Crawford and Graskopf (1984) suggests that the aperture size of a groutable fracture should be at least three times the maximum grain size (d95) of the used cement. However, this rule is mainly applicable on old grout recipes without additives and admixtures (e.g. superplasticizers) using coarse grained cements (e.g. $d 95>30 \mu \mathrm{m}$ ) with low water-to-cement ratios and is not consistent with the results obtained in this study.

\section{Discussion}

The presented results can be reconsidered and further discussed with respect to the most governing origins of the uncertainties in grout penetrability measurement using the aforementioned instruments. The uncertainties are principally induced by either of or a combination of the applied pressure, the grout volume, the constriction geometry and the evaluation methods.

\subsection{Uncertainties Induced by the Applied Pressure}

One of the deficiencies of ordinary Filter pump is the operator dependency of the applied pressure, which might generate different penetrability for identical grout samples. Uneven and unequal mass flow rates, shown in different repeats with the 54, 61 and $77 \mu \mathrm{m}$ mesh filters in Fig. 9, are due to the non-uniform and dissimilar applied pressures along an experiment and in different repetitions. Comparison with the results of modified Filter pump in Figs. 10 and 11 revealed that the adjustment on the instrument and method undeniably reduced the uncertainties in measurement.

Comparing the values of $b_{\text {min }}$ and $b_{\text {crit }}$ evaluated from Short slot tests with 1 bar pressure (70 and $200 \mu \mathrm{m})$ with those under 15 bar pressure $(<45$ and $50 \mu \mathrm{m}$ ) suggests that diversity in the applied pressure is one of the most governing sources of contradiction in the results of penetrability measurements conducted by different penetrability measuring instruments as expected.

When grouting a fracture in rock, the grout pressure in the vicinity of the borehole is the maximum. Due to the pressure loss during the penetration, the driving pressure which can be mobilized at the grout front decreases. Depending on the grout rheology and the number of the constrictions in the fracture the pressure loss can be substantial. Since penetration at a constriction is dependent on the pressure, it is essential to measure the penetrability with both the high and the low pressures. This implies that, measuring the grout penetrability using Short slot only at high pressure does not yield a satisfactory result applicable in the field. Therefore, evaluating the $b_{c r i t}$ at both the low and the high pressures (e.g. 1 and 15 bar) is crucial to determine the upper and the lower limits of the fracture aperture in rock that a specific grout can penetrate without filtration. 


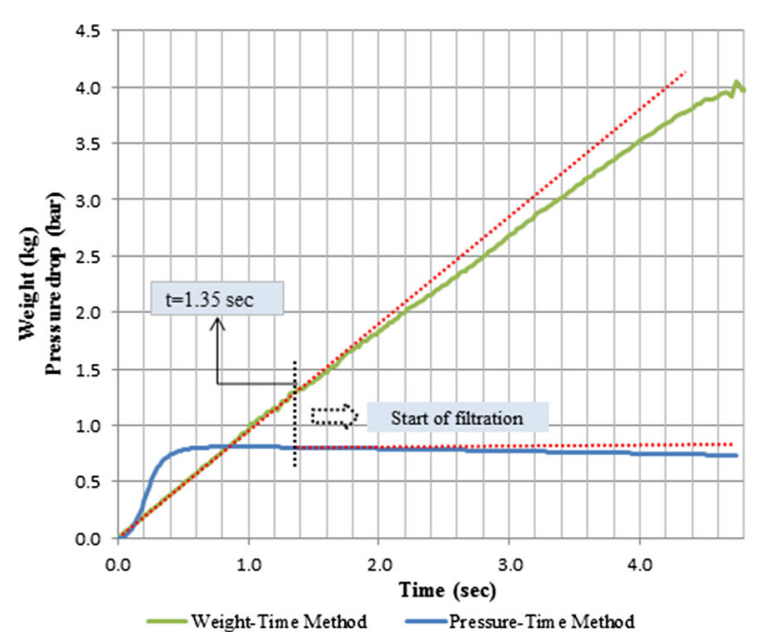

Fig. 15 Penetrability evaluated by modified penetrability meter with $144 \mu \mathrm{m}$ mesh filter using both the weight-time and the pressure-time measurements

The quality of the grout passed through a constriction mainly depends on the size of the constriction and the rheological properties of the injected grout. If the constriction size is larger than $b_{\text {crit }}$, there will be no filtration and therefore no change in the quality of the grout passed through the constriction. If the constriction size is between $b_{\text {min }}$ and $b_{c r i t}$, filtration of the cement particles occurs at the constriction. The smaller the constriction size the higher the filtration and therefore the lower the quality of the grout passed through the constriction. This is due to the fact that the number of cement particles passed through the constriction will be lower and therefore the grout passed through the constriction will be thinner with lower density, apparent viscosity, and yield stress. Similar result is expected when the injected grout is thicker. The higher the density, viscosity, and yield stress, the more the filtration of the cement particles in the same constriction size (if the constriction size is between $b_{\min }$ and $b_{c r i t}$ ) and consequently the lower would be the quality of the passed grout through the constriction.

\subsection{Uncertainties Induced by the Grout Volume}

In the experiments with modified Penetrability meter using the weight-time measurement evaluation, the value of $b_{\text {crit }}$ is evaluated as $90 \mu \mathrm{m}$, provided that the amount of passed grout was between 1.0 and $1.5 \mathrm{~kg}$ (Fig. 12). It could also be evaluated as $77 \mu \mathrm{m}$, if the amount of passed grout was less than $1.0 \mathrm{~kg}$. The latter is similar to the results of ordinary and modified Filter pump with $0.3 \mathrm{~L}$ of the passed grout (less than $1.0 \mathrm{~kg}$ ). This implies that one of the other principal origins of the contradiction in the results of different test instruments is the amount/volume dependency of the grout penetrability that suggests the higher the designated grout volume, the greater the value of $b_{\text {crit }}$.

The required grout volume for a proper evaluation of grout penetrability can be determined based on the needed grout volume to inject a real fracture in rock. According to Grøv and Woldmo (2012), a key point to a successful grouting is to focus the injection on the surrounding area of the tunnel edge limited to a radius of 5-10 $\mathrm{m}$. This suggests a minimum penetration length of approximately $5 \mathrm{~m}$ around the tunnel. Assuming disk shape fractures with the apertures of 50,100 , and $200 \mu \mathrm{m}$ and the radius of $5 \mathrm{~m}$ around a grouting borehole, their required grout volume can be calculated as 3.9, 7.8, and $15.7 \mathrm{~L}$ respectively with an average of nearly $10 \mathrm{~L}$. Dividing this disk into four quarters gives the required grout of approximately 2.5 L. The reason for dividing the calculated volume of a disc shaped fracture by four is to obtain a rough estimation of the grout volume that is required to fill that fracture in 1D direction. This will possibly be a reasonable proposal for the designated grout volume in penetrability test instruments that definitely needs further investigation. It should be noticed that the volume of the grout container in Short slot (approximately $2.6 \mathrm{~L}$ ) is very close to this value, whereas the designed grout volume in ordinary and modified Filter pump as well as ordinary penetrability meter is 0.3 and $1 \mathrm{~L}$ respectively. This once again contributes to underestimate the values of the $b_{\min }$ and the $b_{\text {crit }}$.

\subsection{Uncertainties Induced by the Constriction Geometry}

The designated grout volume of $2.6 \mathrm{~L}$ and the applied pressure of 1 bar in Short slot were approximately identical to those in modified Penetrability meter. The remained diversity was in the constriction geometries, i.e. the slot geometry in Short slot with $10 \mathrm{~mm}$ of the constriction length versus the mesh geometry in modified Penetrability meter with $100 \mu \mathrm{m}$ mesh thickness. The associated resisting friction against the grout flow along the constriction length in the mesh geometry is negligible compared with the slot geometry of the same size. This suggests that the pressure loss along the constriction in Short slot is greater than 
modified Penetrability meter. Considering an identical pressure before the constriction in both instruments, a lower driving pressure will reasonably remain at the end of the constriction in Short slot which will reduce the grout penetrability. A higher value of $b_{\min }$ is therefore expected for similar grout using Short slot compared with modified Penetrability meter. The obtained results in this investigation verified that in closely identical conditions the evaluated value of $b_{\text {min }}$ in Short slot $(70 \mu \mathrm{m})$ was greater than that in modified Penetrability meter (35 and $43 \mu \mathrm{m})$ (Figs. 12, 13, 14). The similar values of the $b_{\text {crit }}(200 \mu \mathrm{m})$ evaluated by Short slot and modified Penetrability meter imply that evaluating the $b_{\text {crit }}$ is less influenced by the diversity in the geometry (Figs. 12, 13, 14).

\subsection{Uncertainties Induced by the Evaluation Methods}

In ordinary Filter pump, replacing the total volume of passed grout by the weight-time measurement to evaluate the values of $b_{\text {crit }}$ provided the opportunity to recognize the filtration in the experiments with $77 \mu \mathrm{m}$ mesh filter, which was not possible before (Fig. 9). In modified Filter pump, replacing the old evaluation method by the new one, once again provided the opportunity to identify the filtration in the experiments with $61 \mu \mathrm{m}$ mesh filter, which could not be properly detected previously (Fig. 11). Therefore, the new evaluation method in both ordinary and modified Filter pump undeniably increased the accuracy in the evaluation.

In modified Penetrability meter, both the weighttime and the pressure-time evaluation methods were to reveal the same penetrability. This was verified in Fig. 15, where the start and the evolution of filtration after $1.35 \mathrm{~s}$ presented by both methods simultaneously. In Fig. 13, the value of $b_{\text {crit }}$ obtained from the pressure-time method $(200 \mu \mathrm{m})$ also verified the result of the weight-time method perfectly. However, the pressure-time evaluation appeared more sensitive than the weight-time method in evaluation of the $b_{\text {min }}$.

\subsection{Uncertainties Induced by a Combination of Origins}

The evaluated $b_{\text {min }}$ and $b_{c r i t}$ obtained from Filter pump are significantly lower than those obtained from Short slot in 1 bar pressure (Table 3). This is considered to be in association with all the aforementioned parameters (a)-(d) in the introduction except the pressure. This makes Filter pump not suitable for measuring the $b_{\text {min }}$ and the $b_{\text {crit }}$. However, it can still be used to control the cement quality, i.e., the partial hydration of cement in contact with moisture or to test the quality of mixing as described in SS-EN 14497:2004.

\section{Conclusions}

The most significant outcomes of this investigation are presented as follows:

- Nonuniform and unequal applied pressure was found to be one of the main governing origins of uncertaity and contradition in the results of different penetrability measuring instruments. Evaluating $b_{\text {crit }}$ at both the low and the high pressures, e.g. 1 and 15 bar, was found crucial to determine the upper and the lower limits of a real fracture aperture in rock that a specific grout can penetrate without filtration.

- Difference in the designated grout volume was found the second governing origin of uncertaity and contradition in the results of penetrability measuring instruments. The experiments using modified Penetrability meter clearly illustrated that the higher the designated grout volume, the greater the value of $b_{c r i t}$. The required grout volume for proper evaluating the grout penetrability was also estimated to be approximately $2.5 \mathrm{~L}$. The results of ordinary and modified Filter pump and ordinary Penetrability meter (with the designated grout volume of 0.3 and $1 \mathrm{~L}$ ) will therefore be less than the proper values of the grout penetrability through a real fracture in rock. This makes applicability of those instruments not recommended. However, Filter pump is still useful for quality control of the cement and the mixing process as suggested by Swedish standard SS-EN-14497.

- Diversity in the constriction geometry was found as the third governing origin of uncertainty and contradiction in the results of the penetrability measurements. The evaluated value of the $b_{\min }$ in Short slot was greater than that in modified Penetrability meter in closely identical conditions. This was due to the remained differences in the constriction geometries. However, the similar values of the $b_{\text {crit }}$ obtained from both instruments inferred that evaluating the $b_{\text {crit }}$ is less influenced by the diversity in constriction geometry. 
Acknowledgements This survey was conducted within the frame of Trust 3.3-GeoInfra (http://trust-geoinfra.se). The authors warmly acknowledge the funders of the project, viz. the Rock Engineering Research Foundation (BeFo), the Swedish Transport Administration (Trafikverket), and the Development Fund of the Swedish Construction Industry (SBUF), for their financial and technical supports.

Open Access This article is distributed under the terms of the Creative Commons Attribution 4.0 International License (http:// creativecommons.org/licenses/by/4.0/), which permits unrestricted use, distribution, and reproduction in any medium, provided you give appropriate credit to the original author(s) and the source, provide a link to the Creative Commons license, and indicate if changes were made.

\section{References}

Axelsson M, Gustafson G (2010) The penetracone, a new robust field measurement device for determining the penetrability of cementitious grouts. Tunn Undergr Sp Tech 25(1):1-8. doi:10.1016/j.tust.2009.06.004

Axelsson M, Gustafson G, Fransson Å (2009) Stop mechanism for cementitious grouts at different water-to-cement ratios. Tunn Undergr Sp Tech 24(4):390-397. doi:10.1016/j.tust. 2008.11.001

Crawford AM, Graskopf G (1984) Grout ability ratio for filter blocking of joints in rock. University of Toronto, Department of Civil Engineering, Toronto

Draganovic A, Stille H (2011) Filtration and penetrability of cement-based grout: study performed with a short slot. Tunn Undergr Sp Tech 26(4):548-559. doi:10.1016/j.tust. 2011.02.007

Draganovic A, Stille H (2014) Filtration of cement-based grouts measured using long slot. Tunn Undergr Sp Tech 43:101-112. doi:10.1016/j.tust.2014.04.010

Eklund T (2005) Penetrability due to filtration tendency of cement based grouts. Ph.D. Thesis, Department of Soil and Rock Mechanics, KTH Royal Institute of Technology, Stockholm, Sweden

Eklund D, Stille H (2008) Penetrability due to filtration tendency of cement-based grouts. Tunn Undergr Sp Tech 23(4):389-398. doi:10.1016/j.tust.2007.06.011

Eriksson M, Stille H (2003) A method for measuring and evaluating the penetrability of grouts. In: Proceedings of the $3 \mathrm{rd}$ international conference on grouting and ground treatment, New Orleans, Louisiana, United States, 10-12 Feb 2003. ASCE, pp 1326-1337. doi:10.1061/40663(2003)79

Eriksson M, Dalmalm T, Brantberger M, Stille H (1999) Separations-och filtrerings stabilitet hos cementbaserade injekteringsmedel. Raport 3065 (in Swedish), Royal Institute of Technology

Eriksson M, Friedrich M, Vorschulze C (2004) Variation in the rheology and penetrability of cement-based grouts: an experimental study. Cem Concr Res 34(7):1111-1119. doi:10.1016/j.cemconres.2003.11.023

Fransson $\AA$ (2008) Grouting design based on characterization of the fractured rock, presentation and demonstration of a methodology. In: Technical report R-08-127. Swedish nuclear fuel and waste management AB (SKB), Stockholm

Gandais M, Delmas F (1987) High penetration C3S bentonitecement grouts for finely fissured and porous rock. In: Proceeding of the international conference on foundations and tunnels V2, London, UK, 24-26 Mar 1987, pp 29-33

Grøv E, Woldmo O (2012) Modern pre-grouting technology in Norway. In: Proceedings of the 4th international conference on grouting and deep mixing, New Orleans, Louisiana, United States, 15-18 Feb 2012. ASCE, pp 805-815. doi:10.1061/9780784412350.0064

Gustafson G, Stille H (2005) Stop criteria for cement grouting. Felsbau: Zeitschrift für Geomechanik und Ingenieurgeologie im Bauwesen und Bergbau 23(3):62-68

Gustafson G, Claesson J, Fransson A (2013) Steering parameters for rock grouting. J Appl Math 2013:1-9. doi:10.1155/ 2013/269594

Hansson P (1995) Filtration stability of cement grouts for injection of concrete structures. IABSE Reports = Rapports AIPC = IVBH Berichte 73(1-2):1199-1204. doi:10. 5169/seals-55333

Hernqvist L, Fransson $\AA$, Gustafson G, Emmelin A, Eriksson M, Stille H (2009) Analyses of the grouting results for a section of the APSE tunnel at Äspö Hard Rock Laboratory. Int J Rock Mech Min 46(3):439-449. doi:10.1016/j.ijrmms. 2008.02.003

Hjertström S (2001) Microcement-pentration versus particle size and time control. In: Proceedings of the 4th nordic rock grouting symposium, Stockholm, Sweden, 8 Nov 2001. SveBeFo Rapport, vol 55, pp 61-71

Houlsby AC (1990) Construction and design of cement grouting: a guide to grouting in rock foundations. Wiley, Hoboken

Lombardi G (2003) Grouting of rock masses. In: Proceedings of the 3th international conference on grouting and ground treatment, New Orleans, Louisiana, United States, 10-12 Feb 2003. ASCE, pp 164-197. doi:10.1061/40663(2003)6

Nobuto J, Nishigaki M, Mikake S, Kobayashi S, Sato T (2008) Prevention of clogging phenomenon with high-grouting pressure. Doboku Gakkai Ronbunshuu C 64(4):813-832. doi:10.2208/jscejc.64.813 (in Japanese with English abstract)

Rafi JY, Stille H (2015) Basic mechanism of elastic jacking and impact of fracture aperture change on grout spread, transmissivity and penetrability. Tunn Undergr Sp Tech 49:174-187. doi:10.1016/j.tust.2015.04.002

Rushton A, Ward AS, Holdich RG (2000) Solid-liquid filtration and separation technology, 2nd edn. Wiley-VCH, Weinheim. doi:10.1002/9783527614974.ch01

Sandberg P (1997) NES-metod för mätning av injekteringsbruk inträngningsförmåga. Svensk Bergs- \& Brukstidning 5-6/ 97 (in Swedish)

Stille H (2015) Rock grouting-theories and applications. BeFo Rock Engineering Research Foundation, Stockholm

Stille H, Gustafson G, Hassler L (2012) Application of new theories and technology for grouting of dams and foundations on rock. Geotech Geol Eng 30(3):603-624. doi:10. 1007/s10706-012-9512-7

Warner J (2004) Practical handbook of grouting: soil, rock and structures. Wiley, Hoboken 